\title{
Determination of Radiation Shielding Properties of Cotton Polyester Blend Fabric Coated with Different Barite Rate
}

\begin{abstract}
S. Kilincarslan ${ }^{a *}$, I. AKKURT ${ }^{b}$, I.S. UnCU ${ }^{c}$ And F. AKArslan ${ }^{d}$
${ }^{a}$ Natural and Industrial Building Materials Application and Research Centre, Süleyman Demirel University, 32260, Isparta, Turkey

${ }^{b}$ Department of Physics, Faculty of Arts \& Sciences, Süleyman Demirel University, 32260, Isparta, Turkey

${ }^{c}$ Department of Electrical and Electronic Engineering, Faculty of Technology, Süleyman Demirel University, 32260, Isparta, Turkey

${ }^{d}$ Department of Textile Engineering, Engineering Faculty, Süleyman Demirel University, 32260, Isparta, Turkey

Using radiation in industry and medicine brings its hazardous effects. On account of this, people have started to be exposed to extra radiation. Thus radiation protection is developed in parallel with the utilization of radiation. In order to be protected from radiation three different criteria have to be taken into account, these are time, distance and the shielding. Shielding is the most effective way. An effective shield should cause a large energy loss on a small distance without emission of more hazardous radiation. In the world, more than three-hundred nuclear facilities have been used to fulfill the needs in the fields of scientific research, energy, agriculture and industry. In addition to this in medical centres radiation beams have been used for treatment and diagnosis. It is extremely important to protect the human body from radioactive rays. Barite is a mineral which can be used for shielding because of barium, which is a high atomic number element. The shielding property of barite is utilized in fabrics. Barite coated fabrics having characteristics of retaining radiation was obtained by penetrating barite into the fabrics via coating method. The linear attenuation coefficients $(\mu)$ of the coated barite fabrics were measured at the photon energies of 662,1173 and $1332 \mathrm{keV}$ obtained from ${ }^{137} \mathrm{Cs}$ and ${ }^{60} \mathrm{Co} \gamma$-ray sources, respectively. As detailed elsewhere, the measurement has been performed using the gamma spectrometer that contains $\mathrm{NaI}(\mathrm{Tl})$ connected to $16 \mathrm{k}$ channels multi-channel-analyser. In this study, cotton polyester blend fabric was used. To apply barite mineral to fabric via coating method, it was grinded to a size of 2-10 microns by using jaw crushers. FK $800 / \mathrm{N}$ type transparent compound was used as adhesive. The coated fabrics were prepared with different volumes of barite. For this purposes four different types of fabrics have been produced, where the rate of barite was $0 \%, 40 \%, 50 \%$ and $60 \%$. The results of experiments show that barite coated fabrics have blocked radiation. When barite ratio increases, the amount of absorbed radiation also increases.
\end{abstract}

DOI: 10.12693/APhysPolA.129.878

PACS/topics: $42.88 .+$ h

\section{Introduction}

Using radiation in various fields from industry to medicine brings its hazardous effects. On account of this, people have started to be exposed to extra radiation. Thus radiation protection is developed in physics in parallel with the utilization of radiation. In order to be protected from radiation three criteria have to be taken into account, those are time, distance and the shielding. Shielding is the most effective way. An effective shield should cause a large energy loss on a small distance without emission of more hazardous radiation [1].

In the world, more than three hundred nuclear facilities have been used to fulfill the needs in the fields of scientific research, energy, agriculture and industry. In addition to this in medical centres radiation beams have been used for treatment and diagnosis. It is extremely

\footnotetext{
* corresponding author; e-mail: semsettinkilincarslan@sdu.edu.tr
}

important to protect the human body from radioactive rays [2]. Many studies have been done for the production of fabrics for radiation protection. Some of these studies were conducted on UV protection of fabrics and others were conducted on the electromagnetic radiation conservative fabric production [3-9]. Barite is a mineral which can be used for shielding because of high atomic number of its constituent element barium [10]. The shielding property of barite is utilized in fabrics. Barite coated fabrics having characteristics of retaining radiation was obtained by penetrating barite into the fabrics via coating method.

\section{Materials and methods}

In this study, cotton polyester blend fabric was used. To apply barite mineral to fabric via coating method, it was grinded to a size of $2-10$ microns by using jaw crushers. FK $800 / \mathrm{N}$ type transparent compound was used as the adhesive. Fabrics was produced using the methods of barite covering. The coated fabrics were prepared with different volumes of barite. For this purposes four different types of fabrics, where barite was used in the rate of $0 \%, 40 \%, 50 \%$ and $60 \%$, have been produced. 
The most appropriate coating method was used to penetrate materials into fabric. Micron sized barite was prepared by mixing with adhesive water-based additives at amounts presented in Table I. Water was added for obtaining fluid consistency. Fabric to be coated was fixed on the smooth ground and then silk stretched on metal sash was placed on the surface of that fabric. Glue mixture prepared by adding barite was uniformly perfused on the surface of fabric. Fabrics were kept fixed after the coating process. This process was performed via a succession of heating and cooling. Fixed structure was not destroyed unless a temperature higher than the temperature of fixation was applied.

\section{TABLE I}

Content of the pulp mixture perfused on fabric (weight percent).

\begin{tabular}{c|c|c}
\hline \hline Barite & Adhesive & Water \\
\hline 40 & 30 & 30 \\
50 & 25 & 25 \\
60 & 20 & 20
\end{tabular}

\section{Results and discussion}

The linear attenuation coefficients $(\mu)$ of the coated barite fabrics were measured at the photon energies of 662, 1173 and $1332 \mathrm{keV}$ obtained from ${ }^{137} \mathrm{Cs}$ and ${ }^{60} \mathrm{Co} \gamma$-ray sources, respectively. The linear attenuation coefficients have been evaluated by comparing $N$ and $N_{0}$, which are the measured count rates of the detector with and without the absorber of thickness $x(\mathrm{~cm})$, respectively.

$$
N=N_{0} \mathrm{e}^{-\mu x} \text {. }
$$

The linear attenuation coefficients of clean fabric and coated barite fabric were measured. The results are given in Fig. 1.

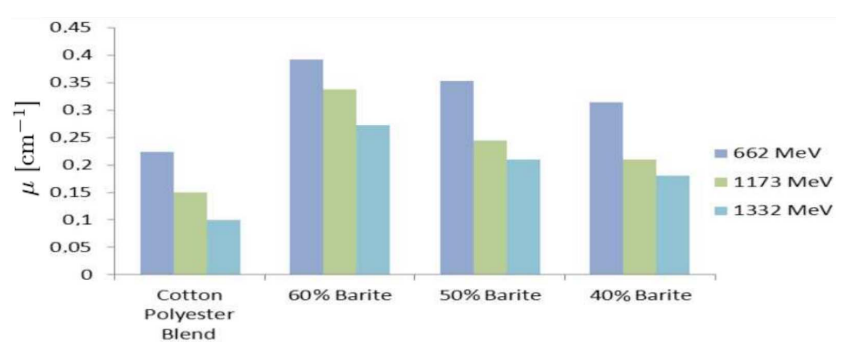

Fig. 1. Measured linear attenuation coefficients for different photon energies and different fabrics.
The results of experiments show that barite coated fabrics have blocked radiation. When barite ratio increases, the amount of radiation absorption also increases.

\section{Conclusions}

It can be seen from this work that the barite amount in the coating is important and the radiation shielding properties can increase with the increasing barite rate. It can also be seen from this work that the energy of gamma rays is important and the linear attenuation coefficients have decreased with the increasing gamma energies. It can be concluded from this work that the cotton polyester fabric coated with barite is an important alternative for the radiation protection.

\section{Acknowledgments}

This work has been supported by TUBITAK under Project number 112M373.

\section{References}

[1] Ş. Kılınçarslan, C. Başyiğit, I. Akkurt, J. Fac. Eng. Arch. 22, 393 (2007).

[2] Ş. Kılınçarslan, Ph.D. Thesis, SDÜ Graduate School of Natural Applied Science, Isparta 2004.

[3] M. Akaydın, Y. İkiz, N. Seyrek Kurban, Textile and Confection 3, 212 (2009).

[4] W.Y. Chiang, K.Y. Cheng, Polym. Compos. 18, 748 (1997).

[5] D. Saravanan, Autex Res. J. 7, 53 (2007).

[6] K. Duran, M.İ. Bahtiyari, R. Atav, Protective Nonwoven Technical Textiles, Ege University, Textile and Confection Research and Application Center, 2007.

[7] T.W. Więckowski, J.M. Janukiewicz, Fibres Text. East. Eur. 5/59, 18 (2006).

[8] I. Algaba, A. Riva, Coloration Technol. 118, 52 (2002).

[9] N. Merdan, K. Acar, Graduate School Journals 8, 1 (2009).

[10] M. Ayan, JMMOB Sayı 7, 59 (1979). 